\title{
Prevention of ethanol and aspirin-induced gastric mucosal lesions by paracetamol and salicylate in rats: role of endogenous prostaglandins
}

\author{
S J KONTUREK*, T BRZOZOWSKI, I PIASTUCKI, and T RADECKI \\ From the Institute of Physiology, Academy of Medicine, Kraków, Poland
}

SUMMARY Paracetamol or sodium salicylate given intragastrically 30 minutes before the administration of absolute ethanol or acidified aspirin dose-dependently reduced the formation of mucosal lesions. The generation of gastric mucosal prostaglandin-like activity increased with ethanol and was completely suppressed by acidified aspirin. Paracetamol or sodium salicylate given alone increased the generation of mucosal prostaglandin-like material. Indomethacin, the prostaglandin synthesis inhibitor, suppressed this effect and inhibited the protective influence of paracetamol or sodium salicylate on the production of gastric lesions.

Prostaglandins given exogenously or released endogenously by mild irritants applied to gastric mucosa can prevent the formation of mucosal lesions induced by aspirin or necrotising agents such as absolute ethanol. ${ }^{12}$

Paracetamol and salicylic acid or its sodium salt are widely used as analgesics but, unlike aspirin, do not induce gastric mucosal damage and may not inhibit prostaglandins biosynthesis in gastric mucosa. ${ }^{3-5}$ Seegers et al. ${ }^{4}$ reported that paracetamol may reduce the formation of acidified aspirin induced mucosal damage in rats and suggested that this may be due to the stimulation of endogenous production of prostaglandins. Similarly, sodium salicylate inhibited the formation of ethanol-induced gastric lesions, suggesting that this substance may act as a mild irritant - that is, to increase prostaglandin biosynthesis. However, gastric mucosal prostaglandins were not measured in this study. ${ }^{6}$

This study was designed to compare the protective effects of paracetamol and sodium salicylate against gastric mucosal lesions induced by ethanol or acidified aspirin and to examine the protective role of mucosal prostaglandins.

\section{Methods}

Wistar rats of either sex, weighing 140-200 g, were fasted for 24 hours before the study but had free access to water until four hours before the

* Address for correspondence: Professor Dr S J Konturek. Institute of Physiology, 31-531 Kraków, Grzegórzecka 16. Poland. experiment when they were placed in individual Bollman cages with wide mesh bottoms to prevent coprophagy.

\section{PRODUCTION OF GASTRIC MUCOSAL LESIONS BY}

ABSOLUTE ETHANOL OR ACIDIFIED ASPIRIN

Drugs were administered intragastrically via a metal orogastric tube. At the end of the experiment the animals were killed, their stomachs were removed and opened along the greater curvature, and the mucosa was examined by an experienced investigator unaware of the treatment given. The surface of each gastric lesions was measured planimetrically to determine the total ulcer area, and expressed in $\mathrm{mm}^{2}$ of mean ulcer area per rat in each tested group of animals. The mucosa of the oxyntic gland area was then prepared for the generation of prostaglandins according to the method described by Whittle. ${ }^{7}$

Several groups of 10-20 rats were used in studies with absolute ethanol: (1) ethanol alone $(1 \mathrm{ml}),(2)$ paracetamol $(10-80 \mathrm{mg} / \mathrm{kg})$ followed 30 minutes later by ethanol, (3) indomethacin $(5 \mathrm{mg} / \mathrm{kg})$ followed 60 minutes later by paracetamol $(80 \mathrm{mg} / \mathrm{kg})$ and then 30 minutes later by ethanol, (4) sodium salicylate $(10-80 \mathrm{mg} / \mathrm{kg})$ followed 30 minutes later by absolute ethanol, (5) indomethacin $(5 \mathrm{mg} / \mathrm{kg})$ followed 60 minutes later by sodium salicylate $(80$ $\mathrm{mg} / \mathrm{kg}$ ) and then 30 minutes later by ethanol, (6) paracetamol alone $(80 \mathrm{mg} / \mathrm{kg})$, (7) sodium salicylate alone $(80 \mathrm{mg} / \mathrm{kg}),(8)$ indomethacin alone $(5 \mathrm{mg} / \mathrm{kg})$, and (9) acidified aspirin alone $(20 \mathrm{mg} / \mathrm{kg})$.

In a series of experiments with gastric ulcers produced by acidified aspirin, the following intra536 
gastric treatments were given: (1) acidified aspirin alone, (2) paracetamol $(80 \mathrm{mg} / \mathrm{kg})$ followed 30 minutes later by acidified aspirin, (3) indomethacin $(5 \mathrm{mg} / \mathrm{kg})$ followed 60 minutes later by paracetamol $(80 \mathrm{mg} / \mathrm{kg}$ ) and then by acidified aspirin, (5) indomethacin $(5 \mathrm{mg} / \mathrm{kg})$ followed 60 minutes later by sodium salicylate $(80 \mathrm{mg} / \mathrm{kg})$ and then by acidified aspirin, and (6) unacidified aspirin (20 $\mathrm{mg} / \mathrm{kg}$ ) followed 30 minutes later by acidified aspirin. In all experiments (except when indicated) acidified aspirin was administered in a bolus injection of $60 \mathrm{mg} / \mathrm{kg}$ followed by a constant infusion of $42 \mathrm{mg} / \mathrm{kg} / \mathrm{h}$ plus $0.15 \mathrm{M} \mathrm{HCl}$ at a rate of $4 \mathrm{ml} / \mathrm{h}$.

The solutions of all test substances were freshly prepared just before the experiment and given intragastrically 30 or 60 minutes before the intragastric administration of the damaging agent, absolute ethanol or acidified aspirin.

The animals were killed one hour after intragastric administration of absolute ethanol and three hours after the beginning of intragastric administration of acidified aspirin. All test solutions were freshly prepared just before the experiment.

\section{MEASUREMENT OF GASTRIC MUCOSAL \\ PROSTAGLANDINS}

Portions of gastric mucosa were carefully stripped off from the oxyntic gland area and placed in ice-cold $0.05 \mathrm{M}$ Tris buffer $\mathrm{pH} 9 \cdot 0$. Samples of tissue of about $300 \mathrm{mg}$ were finely cut with scissors, blood and debris were washed out by shaking for five seconds with $1 \mathrm{ml}$ ice-cold Tris buffer, and centrifuged at $9000 \mathrm{~g}$ for 10 seconds. After discarding the supernatant, fresh Tris buffer was added in the proportion of $1 \mathrm{ml} / 300 \mathrm{mg}$ tissue, mixed for one minute at room temperature using a steady speed of a vortex stirrer, and centrifuged at $9000 \mathrm{~g}$ for 15 seconds. Immediately after centrifugation, aliquots $(5-50 \mu \mathrm{l})$ of supernatant were tested for $\mathrm{PGI}_{2}$-like activity by determining their ability to inhibit aggregation of rabbit platelets in response to ADP $(2 \mu \mathrm{M})$. $\mathrm{PGI}_{2}$ was used as a reference, and generated $\mathrm{PGI}_{2}$-like activity was expressed as $\mathrm{ng} / \mathrm{g}$ wet gastric mucosa. The threshold sensitivity to detect $\mathrm{PGI}_{2}$ was about $0.5 \mathrm{ng} / \mathrm{ml}$. The validation and the sensitivity of this technique is presented elsewhere. $^{2}$

The values reported mean \pm SEM, were analysed using Student's $t$ test for unpaired data.

\section{Results}

EFFECT OF PARACETAMOL AND SODIUM

SALICYLATE ON ETHANOL-INDUCED GASTRIC LESIONS AND MUCOSAL GENERATION OF PGI 2 . All 20 control rats given absolute ethanol intra- gastrically developed severe mucosal damage in the oxyntic gland area as described previously. ${ }^{1}$ The antral portion was less affected, while the forestomach had no visible lesions. Mucosal lesions consisted of elongated bands of necrosis with the mean area amounting to $101 \cdot 4 \pm 9 \cdot 1 \mathrm{~mm}^{2}$ per rat (Fig. 1).

The generation of $\mathrm{PGI}_{2}$-like activity in oxyntic mucosa of untreated rats fasted for 24 hours averaged $221 \pm 35 \mathrm{ng} / \mathrm{g}$. Ethanol increased the amounts of $\mathrm{PGI}_{2}$-like activity to $325 \pm 63 \mathrm{ng} / \mathrm{g}$ (Fig. 2).

Pretreatment of gastric mucosa with paracetamol or sodium salicylate at a dose of $80 \mathrm{mg} / \mathrm{kg}$ significantly $(\mathrm{p}<0.01)$ reduced ethanol-induced gastric lesions by about $97 \%$ and $85 \%$, respectively (Fig. 1).

Lower doses of these agents caused smaller does-dependent reduction in ethanol induced necrosis (Table 1). The doses causing $50 \%$ inhibition $\left(E_{50}\right)$ were about $28 \mathrm{mg} / \mathrm{kg}$ for paracetamol and $8.7 \mathrm{mg} / \mathrm{kg}$ for sodium salicylate. The generation of $\mathrm{PGI}_{2}$ by oxyntic mucosa treated with ethanol plus paracetamol or sodium salicylate was not significantly different from that by mucosa from rats treated with ethanol alone ( $p>0 \cdot 10$, Fig. 2 ).

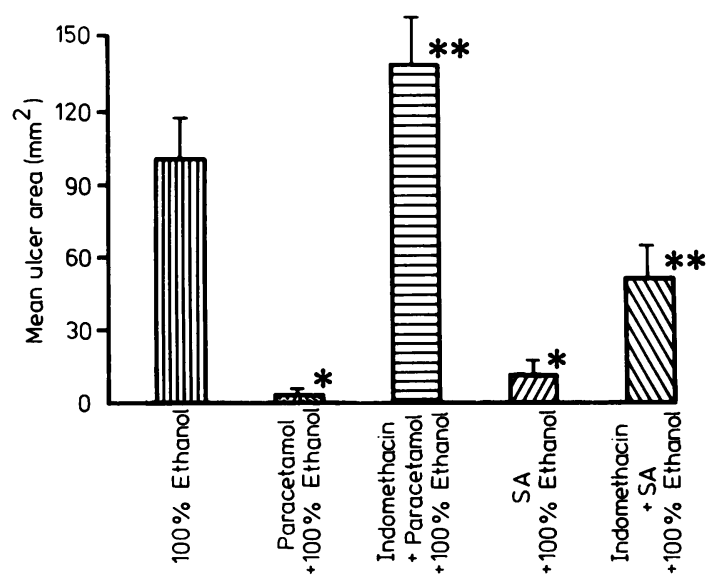

Fig. 1 Mean area of gastric lesions induced by absolute ethanol $(1 \mathrm{ml})$ given intragastrically alone or in combination with paracetamol or sodium salicylate $(80 \mathrm{mg} / \mathrm{kg})$ with and without pretreatment with indomethacin $(5 \mathrm{mg} / \mathrm{kg})$. Each column represents mean $\pm S E M$ of results from six to 20 rats. * Significant $(p<0.01)$ decrease below the control value obtained with ethanol alone. ${ }^{* *}$ Significant $(p<0.05)$ increase above value obtained with the combination of ethanol and paracetamol or sodium salicylate. 


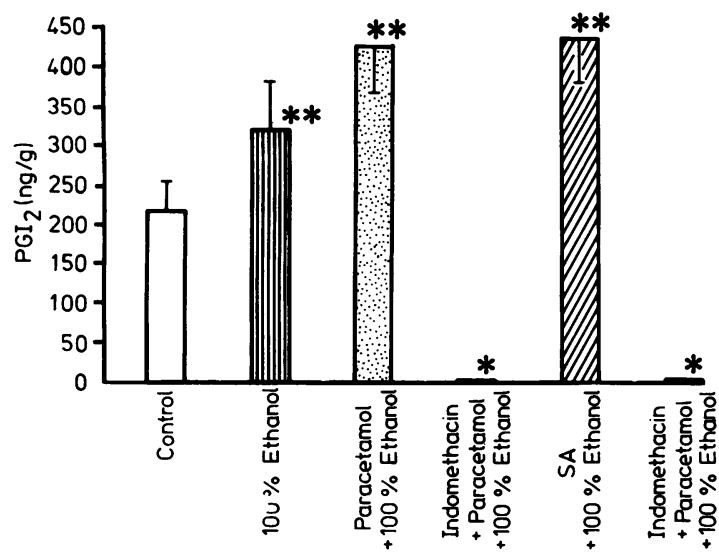

Fig. 2 Generation of $\mathrm{PGI}_{2}$-like activity by oxyntic mucosa of 10 untreated rats and those given treatments described in Fig. 1. * Significant $(p<0.01)$ decrease below the control value. ${ }^{* *}$ Significant $(p<0.05)$ increase above control value obtained in untreated rats.

Indomethacin $5 \mathrm{mg} / \mathrm{kg}$ given intragastrically 60 minutes before the combination of ethanol plus paracetamol or sodium salicylate increased significantly $(p<0.05)$ the area of mucosal lesions above the values obtained with the combination alone (Fig. 1). The inhibition by indomethacin of protection by paracetamol against ethanol-induced damage was complete, and protection by sodium salicylate was reduced by about $50 \%$. The pretreatment with indomethacin or acidified aspirin increased significantly $(\mathrm{p}<0.05)$ the mean area of the ethanolinduced lesions by about $30 \%$ and $24 \%$, respectively (Table 1). Indomethacin or acidified aspirin alone or in combination with other drugs almost completely suppressed the generation of $\mathrm{PGI}_{2}$-like activity (Fig. 2, Table 2).

Table 1 Effect of pretreatment with various doses of paracetamol, sodium salicylate, indomethacin, or acidified aspirin on ethanol-induced gastric lesions

\begin{tabular}{|c|c|c|c|c|}
\hline & $(m g / k g)$ & $\begin{array}{l}\text { No. } \\
\text { of } \\
\text { rats }\end{array}$ & $\begin{array}{l}\text { Mean lesion } \\
\text { area } \\
\left(\mathrm{mm}^{2}\right)\end{array}$ & $\begin{array}{l}\text { Change } \\
\text { from } \\
\text { control } \\
(\%)\end{array}$ \\
\hline \multicolumn{5}{|l|}{$100 \%$ Ethanol } \\
\hline Control & & 20 & $101 \cdot 4 \pm 9 \cdot 1$ & - \\
\hline \multirow{3}{*}{ + Paracetamol } & 10 & 6 & $61 \cdot 18 \pm 8 \cdot 3^{*}$ & $-39 \cdot 7$ \\
\hline & 20 & 7 & $39.85 \pm 11.4^{*}$ & $-60 \cdot 8$ \\
\hline & 80 & 6 & $2 \cdot 75 \pm 0.9^{*}$ & $-97 \cdot 3$ \\
\hline \multirow[t]{3}{*}{ + Sodium salicylate } & 10 & 6 & $56 \cdot 42 \pm 9 \cdot 5^{*}$ & $-44 \cdot 4$ \\
\hline & 20 & 12 & $10 \cdot 04 \pm 5 \cdot 4^{*}$ & $-90 \cdot 1$ \\
\hline & 80 & 6 & $2 \cdot 75 \pm 0.6^{*}$ & $-97 \cdot 3$ \\
\hline + Indomethacin & 5 & 6 & $131 \cdot 8 \pm 11 \cdot 5^{*}$ & $+30 \cdot 0$ \\
\hline + Acidified aspirin & 20 & 6 & $125 \cdot 7 \pm 8 \cdot 8^{*}$ & $+24 \cdot 0$ \\
\hline
\end{tabular}

* Significant $(p<0.05)$ change from control value.
Table 2 Effect of paracetamol, sodium salicylate, indomethacin, or acidified apirin alone given for 4.5 hours on ulcer formation and generation of $P G I_{2}$-like activity in oxyntic mucosa

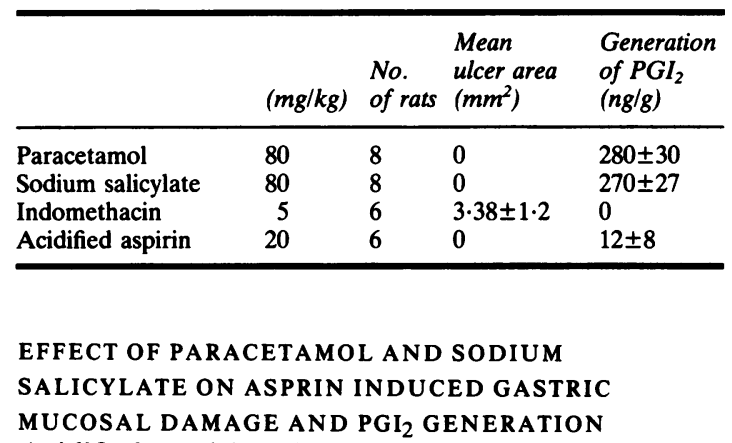

Acidified aspirin given intragastrically produced mucosal damage occurring mainly in the oxyntic mucosa. The mean ulcer area was $35.3 \pm 5.0 \mathrm{~mm}^{2}$ (Fig. 3). Pretreatment of rats with sodium salicylate or paracetamol $(80 \mathrm{mg} / \mathrm{kg})$ reduced the mean ulcer area by $72 \%$ and $68 \%$, respectively. Indomethacin $(5 \mathrm{mg} / \mathrm{kg}$ ) completely inhibited the cytoprotection by paracetamol or sodium salicylate. The generation of $\mathrm{PGI}_{2}$-like material in oxyntic mucosa was almost completely suppressed by acidified asprin or indomethacin given alone or in combination with other drugs and these data are not presented.

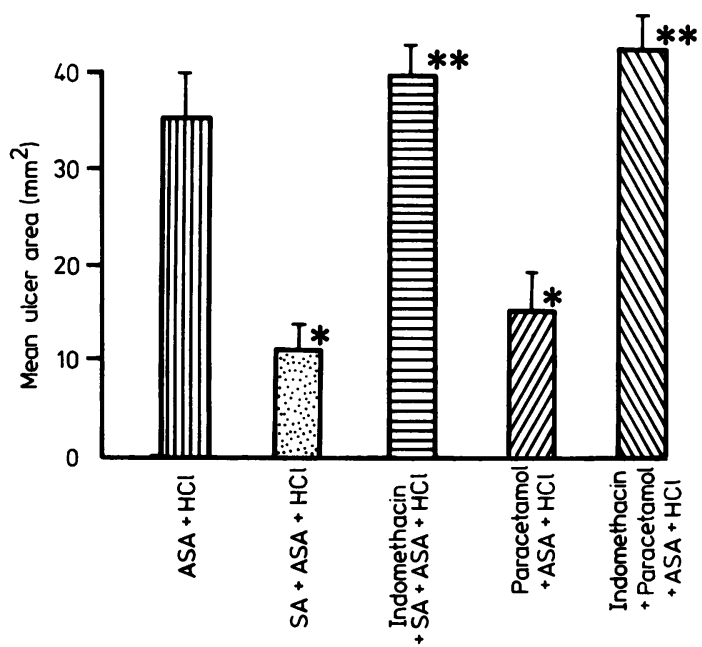

Fig. 3 Mean ulcer area of gastric ulcers induced by acidified aspirin given intragastrically alone or in combination with paracetamol or sodium salicylate with and without pretreatment with indomethacin. Each column represents mean $\pm S E M$ of results in six to 20 rats. * Significant $(p<0.05)$ decrease below control value with acidified aspirin alone. ${ }^{* *}$ Significant $(p<0.05)$ increase above value obtained in rats treated with combination of acidified aspirin and sodium salicylate or paracetamol. 
Indomethacin $(5 \mathrm{mg} / \mathrm{kg})$ or acidified aspirin $(20$ $\mathrm{mg} / \mathrm{kg}$ ) given intragastrically 30 minutes before the standard dose of acidified aspirin slightly increased the mean ulcer area. These small doses of indomethacin or acidified aspirin given intragastrically alone caused little or no change in gastric mucosa but suppressed the generation of $\mathrm{PGI}_{2}$ by about $100 \%$ and $96 \%$ of control values found in untreated mucosa (Table 2).

\section{Discussion}

This study demonstrates that paracetamol and sodium salicylate, which by themselves increase the generation of mucosal prostaglandins, dosedependently reduced gastric mucosal damage induced by absolute ethanol or acidified aspirin.

Gastric mucosa of rats $^{27-9}$ and other species ${ }^{10} 11$ can form $\mathrm{PGE}_{2}$ and $\mathrm{PGI}_{2}$ and, in rats, $\mathrm{PGI}_{2}$ production predominates. ${ }^{2}$

Two different models of gastric lesions were produced in this study. With ethanol, ${ }^{1}$ the gastric mucosa showed large areas of necrosis confined mostly to the oxyntic portion and exhibited an increased capability of generating $\mathrm{PGI}_{2}$-like material. The damage was presumably due to direct action of ethanol on the mucosa and obviously did not result from the deficiency of mucosal prostaglandins. The increased generation of $\mathrm{PGI}_{2}$-like material by ethanol may have been due to cellular trauma and mucosal necrosis. Exogenous prostaglandins, however, given in substantial amounts just before the administration of absolute ethanol dose-dependently protected the mucosa against damage by ethanol. ${ }^{1}$ Our present finding, that paracetamol or sodium salicylate inhibited ethanol-induced mucosal necrosis, may be due to stimulation of mucosal generation of prostaglandins. This possibility is supported by our finding that indomethacin prevented the protective effect of paracetamol and sodium salicylate and suppressed mucosal generation of prostaglandins.

Gastric lesions with acidified aspirin intragastrically consisted of multiple erosions and frank bleeding ulcerations in the oxyntic mucosa. There was almost complete inhibition, however, of the mucosal generation of prostaglandins. Loss of normal protection by endogenous prostaglandins is considered to be the major factor in the pathogenesis of acidified aspirin-induced gastric ulcerations. ${ }^{2} 7$ Protection by paracetamol or sodium salicylate against aspirin-induced gastric ulcerations cannot be simply attributed to mucosal generation of prostaglandins, however, because $\mathbf{P G I}_{2}$ synthesis was almost totally inhibited by acidified aspirin. Perhaps stimulation of synthesis before administra- tion of acidified aspirin induces a long-lasting protection. In agreement with this, we found that the pretreatment of mucosa with indomethacin which by itself caused little visible damage to the mucosa (Table 2) but greatly reduced the generation of $\mathrm{PGI}_{2}$-like material, almost completely inhibited the cytoprotection with paracetamol or sodium salicylate. Another possibility is that paracetamol or sodium salicylate blocked access of acidified aspirin to the site on the cyclo-oxygenase.

There is a strong and consistent association between gastric mucosal damage and the intake of acidified aspirin, ${ }^{12}{ }^{13}$ which irreversibly acetylates and inactivates gastric mucosal cyclo-oxygenase. ${ }^{14}$ There is, however, little evidence to associate paracetamol or sodium salicylate with gastric damage. The combination of acidified aspirin plus paracetamol or sodium salicylate was reported to produce fewer gastric erosions than acidified aspirin alone. ${ }^{4}$ Paracetamol, unlike acidified aspirin, did not affect gastric mucosal potential difference ${ }^{15}$ and gastric cell loss in man. ${ }^{3}$ In our recent study ${ }^{16}$ paracetamol $2.5 \mathrm{~g}$ daily for two days in healthy men produced little or no intolerance and only mild gastroscopic mucosal changes, with little effect on prostaglandin biosynthesis. It remains to be established whether chronic administration of paracetamol or sodium salicylate can decrease the risk of human gastric mucosal damage when given with acidified aspirin or other injurious agents.

\section{References}

1 Robert A, Nezamis JE, Lancaster C, Hanchar AJ. Cytoprotection by prostaglandins in rats: prevention of gastric necrosis produced by alcohol, $\mathrm{HCl}, \mathrm{NaOH}$, hypertonic $\mathrm{NaCl}$ and thermal injury. Gastroenterology 1979; 77: 443-43.

2 Konturek SJ, Piastucki I, Brzozowski T. Radecki T, Dembińska-Kieć A, Zmuda A, Gryglewski R. Role of prostaglandins in the formation of aspirin induced gastric ulcers. Gastroenterology 1981; 80: 4-9.

3 Ivey KJ, Silvoso GR, Krause WJ. Effect of paracetamol on gastric mucosa. $B r$ Med J 1978; 1: 1586-8.

4 Seegers AJM, Jager LP, van Nordwijk J. Gastric erosions induced by analgesic drug mixtures in the rat. J Pharm Pharmacol 1978; 30: 84-7.

5 Whittle BJR, Higgs GA, Eakins KE. Selective inhibition of prostaglandin production in inflammatory exudates and gastric mucosa. Nature (Lond) 1980; 284: 271-3.

6 Robert A. Gastric cytoprotection by sodium salicylate. Gastroenterology 1981; 80: 1262.

7 Whittle BJR. Potential endogenous inhibitor of 
prostaglandin synthetase in plasma failure to inhibit cyclo-oxygenase in platelets and the gastric mucosa. $J$ Pharmac Pharmacol 1978; 30: 467-8.

8 Whittle BJR. Temporal relationship between cyclooxygenase inhibition, as measured by prostacyclin biosynthesis, and the gastrointestinal damage induced by indomethacin in the rat. Gastroenterology 1981; 80: 94-8.

9 Moncada S, Salomon JA, Vane JR, Whittle BJR. Formation of prostacyclin $\mathrm{PGI}_{2}$ and its product, 6-oxoPGF $_{1 \alpha}$ by the gastric mucosa of several species. $J$ Physiol (Lond) 1978; 275: 48-58.

10 Le Duc LE, Needleman P. Regional localization of prostacyclin and thromboxane synthesis in dog stomach and intestinal tract. J Pharmacol Exp Ther 1979; 211: 181-8.

11 Konturek SJ, Radecki T, Brzozowski T, Piastucki I, Dembińska-Kieć A. Prostaglandin $\mathrm{E}$ in gastric mucosa and its role in the prevention of ulcers induced by acetyl salicylic acid in cats. Digestion 1981; 21: 205-13.

12 Levy M. Aspirin use in patients with major upper gastrointestinal bleeding and peptic ulcer disease. $N$ Engl J Med 1974; 290: 1158.

13 Cameron AJ. Aspirin and gastric ulcer. Mayo Clinic Proc 1975; 50: 565-70.

14 Vane JR. Inhibition of prostaglandin synthesis as a mechanism of action for aspirin-like drugs. Nature (Lond) 1971; 231: 232-5.

15 Ivey KJ, Settree P. Effect of paracetamol acetaminophen on gastric ionic fluxes and potential differences in man. Gut 1976; 17: 916-9.

16 Konturek SJ, Obtutowicz W, Sito E, Oleksy J, Wilkoń S, Kieć-Dembińska A. Distribution of prostaglandins in gastric and duodenal mucosa of healthy subjects and duodenal ulcer patients. Effects of aspirin and paracetamol. Gut 1981; 22: 283-9. 